\title{
Predictors of malnutrition among older adults aged above 65 years in eastern Ethiopia: neglected public health concern
}

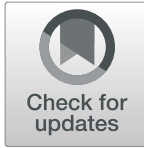

\author{
Abdu Oumer Abdu*, Imam Dagne Yimamu and Ahmed Ale Kahsay²
}

\begin{abstract}
Background: A nutritional problem, especially under nutrition is one of the common public health problems in older population causing greater mortality and economic loss in developing countries. However, evidences on the risk factors for increased nutritional risk among older population is not well stated in Ethiopia. This study aimed to assess the nutritional status and predictors of malnutrition among older adults ( $>=65$ years) in Eastern Ethiopia.

Methods: A community-based analytical survey was conducted among randomly selected 592 older people aged above 65 years of age in Harari region. Subjects were selected using multistage sampling pretested Full Mini Nutritional Assessment (MNA) tool was used to classify as malnourished (MNA score < 17), at risk of malnutrition (MNA score of 17 to 23.5) and otherwise normal. Validated geriatric depression scale short form (15 items) was employed to screen for depression. Data were presented using statistical tables, frequency, percentage, and graphs. Ordinary logistic regression was employed to identify predictors of malnutrition and plum method was used to generate odds ratio. The level of statistical significance was declared at $P$-value less than $5 \%$. Chi-square test, crude and adjusted odds ratio with 95\% confidence was reported.
\end{abstract}

Results: A total of 592 respondents (93.4\%) were interviewed. About 306 (51.7\%) and 93 (15.7\%) were found to be at risk of malnutrition and malnourished respectively. The predicted log odds of being malnourished was higher among those from rural residents ( $A O R=2.08: 1.25-3.45)$, not on working $(A O R=1.31: 95 \% \mathrm{Cl}: 0.87-1.95)$ and did not have health insurance (AOR $=1.58 ; 95 \% \mathrm{Cl} ; 0.97-2.58)$. Those with chronic pain ( $\mathrm{AOR}=1.70 ; 95 \% \mathrm{Cl}: 1.15-2.51$ ), previous hospitalization ( $\mathrm{AOR}=1.59: 95 \% \mathrm{Cl}: 1.27-2.38)$ and not able to cover their personal expense $(\mathrm{AOR}=1.61$ : 95\% Cl: 1.12-2.30) were predictors of malnutrition. The relationship between previous hospitalizations with malnutrition among older adults people is moderated significantly by the presence of chronic pain $(\beta=0.113, p=$ 0.015).

Conclusions: Malnutrition among old age is a public health concern that needs attention. Economical vulnerability, residence, depression, presence of chronic disease, and hospitalization were important risk factors for malnutrition among old age.

Keywords: Malnutrition, Older adults, Mini nutritional assessment, Ethiopia

\footnotetext{
* Correspondence: phnabu@gmail.com

'Department of Public Health, Dire Dawa University, Dire Dawa, Ethiopia

Full list of author information is available at the end of the article
}

(c) The Author(s). 2020 Open Access This article is licensed under a Creative Commons Attribution 4.0 International License, which permits use, sharing, adaptation, distribution and reproduction in any medium or format, as long as you give appropriate credit to the original author(s) and the source, provide a link to the Creative Commons licence, and indicate if changes were made. The images or other third party material in this article are included in the article's Creative Commons licence, unless indicated otherwise in a credit line to the material. If material is not included in the article's Creative Commons licence and your intended use is not permitted by statutory regulation or exceeds the permitted use, you will need to obtain permission directly from the copyright holder. To view a copy of this licence, visit http://creativecommons.org/licenses/by/4.0/ The Creative Commons Public Domain Dedication waiver (http://creativecommons.org/publicdomain/zero/1.0/) applies to the data made available in this article, unless otherwise stated in a credit line to the data. 


\section{Background}

Owning to demographic transition and advances in medical technologies, the world population structure is changing. Worldwide as of 2015, there are 617.1 million older peoples above 65 years with almost $7.6 \%$ of the world Population [1]. In Africa, for example, the life expectancy has risen to about 65 years and accounts for $3.5 \%$ (40million) in 2015 [2]. While, in Ethiopia, 3.2\% of the population were older than 65 years [3].

Global health issues for older age include nutritional problems, chronic non-communicable diseases like heart disease, stroke, and others. A nutritional problem, especially undernutrition is one of the common public health problems in the older adults causing greater mortality and economic loss facing the older population in developing countries [4]. Ethiopia is a country with emerging nutritional problems with its adverse health consequences $[4,5]$. Early detection of malnourished and at risk for malnutrition will be valuable in targeting public health interventions among the older population.

Mini Nutritional Assessment (MNA) is an important validated tool used to assess older adults who are malnourished and at risk of malnutrition. It will be administered in MNA short form (MNA-SF) or the full-length screening tools (18 items) $[6,7]$ even if, both have been validated for use in malnutrition screening among old age population. It helps to identify malnutrition early before severe malnutrition with protein depletion happens. It has better performance in sensitivity and specify than Malnutrition Universal Screening Tools in the identification of malnourished ones [8].

Nowadays due to numerous social structural changes, this segment of the population is being with less care. Also only half of the older adults people have a private house while, about $10 \%$ live without a private home, in mosques and churches [9]. It is estimated that $15-50 \%$ of the older adults are affected by malnutrition in the community while in hospital settings $20-60 \%$ of older adults were affected by malnutrition [10].

In Ethiopia, almost a third of the older adults has one or more visual, mobility, weakness, or hearing difficulty which affects people's access, and utilization of food. Moreover, some older adults have pension while the majority of the rural depends on their relative for support [9].

Globally, malnutrition is estimated to affect one in every six population; it is still increasing along with increased aging [7]. Especially, those with cognitive decline, hospitalized or institutionalized are at greater risk of malnutrition than community dwellers [7]. Similarly, malnutrition results in twice the risk of long term mortality, three times increased the risk of infection and longer period of hospitalization, increasing the health care costs. Malnutrition among older adults also increase the rate of hospital readmission by $30 \%$ which places huge financial burdens on government and individuals [11]. Despite this huge burden, malnutrition is still underreported due to lack of regular malnutrition screening [8].

Malnutrition among old age above 65 years has a devastating impact on morbidity, mortality, increasing the health care cost [8]. A follow-up study showed that those old age at risk of malnutrition and malnourished had 60 and 33.7\% cumulative survival after 3 years. Also, the hazards of all-cause mortality were increased from 56 to $71 \%$ [12].

Despite malnutrition is being major public health problem among older adults, there are a limited studies in Ethiopia $[12,13]$ showing malnutrition is a common problem affecting from 9 to $22 \%$ in the northwest Ethiopia [14]. Along with limited studies, previous studies were unable to use an appropriate screening tools and unable to pinpoint major predictors of malnutrition among the older adults in Ethiopian setting for action to be taken. Thus, particular research was to generate reliable evidences on magnitude of malnutrition and its context-specific risk factors using reliable and validated tools for better geriatric health.

\section{Objective of the study}

To assess the nutritional status and predictors of malnutrition among older adults ( $>=65$ years) residing in Harari region, Eastern Ethiopia.

\section{Methods}

\section{Study area and period}

This study was conducted in Harari region, Eastern Parts of Ethiopia. Harar is found about $526 \mathrm{kms}$ far from Addis Ababa, capital city of Ethiopia. According to the Ethiopian central statics authority's 2007 report, Harari region has a total population of 183, 344 of whom 92,258 were men and 91,086 women and majority of its population lives in 99,321 or $54.17 \%$ of the population lives in urban (CSA 2007 report). Ethnic groups in the region include the Oromo (52.3\%), Amhara (32.6\%), Harari (7.1\%) and others like Tigre and Guraghe etc. According to 2010 Harari Region population projection there are 250, 093 with 146, 913 living in urban and 122, 942 are male with total house hold of 64, 334 .

According to Ethiopian demography, 2018 [15], in Ethiopia $2.91 \%$ of the population are Older adults above 65 years of age. Using this conversion factor the expected number of older adults was calculated and estimated. This Quantitative cross sectional study was conducted from March 01 to 30, 2019.

\section{Population and eligibility}

All older adults aged $>=65$ years of age in Harar region were the target population for this study to which the result is considered to be applied. While, those randomly 
selected people age greater than or equals to 65 years from the selected kebeles, were study population and included in the current survey. Those community dwellers aged above or equals to 65 years with or without their care givers residing in the selected kebles (lower administrative unit in Ethiopia) were included in the current survey. Those older adults who have no any caregiver and unable to communicate and give information were excluded from the study as we are unable to get reliable data from them. In addition, those who were not volunteers to take part in the survey were also excluded from the study. Study subjects with severe spinal curvature (kyphosis or scoliosis), both extremities amputation were not included in the study as this makes plausible measurement of height difficult for reliable body mass index measurement.

\section{Sample size determination}

To determine the minimum sample size for the first objective, single proportion samples size formula with $\mathrm{P}$ as prevalence of malnutrition from the previous study (21.9) [14], 95\% confidence level, "Z" critical value at 95\% CI and marginal error of "d" 5\% and became 263.

$$
n=\frac{(Z \alpha / 2)^{2}}{\frac{P(1-P)}{d^{2}}}
$$

For factors associated with malnutrition the sample size is determined using OpenEpiSave software for cross sectional survey taking empirical statistics like odds ratio, proportion of exposed with malnutrition and power of $80 \%$, with ratio of exposed to non-exposed as 1 and $5 \%$ level of significance. Taking the larger sample size calculated from objective two (286), design effect of 2 , and $10 \%$ non-response rate, the final sample size was $(572+0.1(572))=630$. Thus, this study tried to interview and include 630 study subjects (older adults).

\section{Sampling procedures}

Multi stage sampling was used to select eligible older adults from randomly selected Kebles from each Woreda. Then from each selected woredas using simple random sampling, we select two Kebles randomly from each woreda. Then the sample size was proportionally allocated for each respective selected woredas and then to the selected Kebles. The allocated number of older adults were interviewed from each randomly selected kebeles. Then, the data collector located the center of the kebeles and then randomly select a random direction using random spinning a pen. Then all $\mathrm{HHs}$ with older adults were interviewed in that selected direction until the sample size is achieved. However, when the required sample size is not achieved, another random direction were selected in the similar way and data collected similarly.

\section{Data collection methods}

Data were collected using set of structured questionnaires including socio demographic situations, full mini nutritional Assessment (MNA-full) [7], geriatrics depression scale (GDS-SF), psycho social issues and others. The contextualized data collection tool is attached as supplementary file with this paper (English Version of Questionnaire). Data were collected by trained graduating health science students from house to house visit. Data collectors interviewed the elders and/or the care giver where communication become difficult. The interview was administered in respondent's language they can.

The full MNA tool is worldwide validated too with $80 \%$ specificity and $90 \%$ sensitivity making it as the best, effective, affordable and quick malnutrition screening tool among older adults. It has also showing greater importance in identifying overt malnutrition and risk of malnutrition early, for effective public health interventions [16]. Thus the full MNA tool was contextualized, translated to Amharic and pretested before data collection. The full MNA score tool approved by Nestle Institute which contain 18 items were used with translation and it is published in [7].

The weight of the subjects were measured using calibrated electronic weighting scale to the nearest $0.1 \mathrm{~kg}$. The height was measured using adult stadiometre for those who can stand. While for those who are unable to stand the Arm span from the sterna notch to tip of finger or knee height was to be used as proxy indicator for height of the subjects using specific formula for the specific sex, ethnic group. The BMI was calculated by dividing the weight in $\mathrm{Kg}$ by the height in $\mathrm{m}$ square and was expressed in $\mathrm{kg} / \mathrm{m}^{2}$. However when the height measurement is not possible, calf circumference was used instead of BMI and the status was classified according to the nestle recommendations [7].

The mid upper arm circumference (MUAC) was measured using non-stretchable tape meter on the left arm at midpoint between the acromion process of clavicle and elbow joint. It was measured in arm extended and recorded in centimeter. Short twenty four hour dietary recall was used to assess the dietary intake pattern of the clients, as it reduce the recall bias secondary to memory lapse.

The geriatric depression score was used to assess the psychological condition off the older adults. A fifteen item depression scale assessment were used by direct interviewing the respondent. This tool has shown almost equal sensitivity in identifying depression level which have direct influence on malnutrition among older adults. 


\section{Data quality assurance}

Pair of trained graduating health students were employed to collect the data from study subjects as anthropometric measurement need curiosity and two individuals during measurement. Two day training appropriate interview techniques, anthropometric measurements like height and weight, practices were performed before actual data collection. After that constructive feedbacks were given for the data collectors by investigators and supervisor until they become clear of the checklist implementation. Anthropometric reliability assessment were done on 10 study subjects and inter and interobserver variation were calculated. Cranach's Alpha measure of reliability used and kappa above 0.7 were considered acceptable and all within the acceptable range. All standard measuring procedures and instruments were strictly followed while data collection. During data entry in to EpiData the data quality was kept by making legal ranges, skipping patterns, appropriate coding and careful data entry. The intra observer and inter observers technical error of measurement were calculated after training of the data collectors and supervisors, to measure the reliability of the weight and height anthropometric measurements.

\section{Methods of data analysis}

After checking for completeness ad inconsistencies, the collected data were entered in to EpiData Version 3.02 and Exported to SPSS version 20.0 for analysis. The data is presented in tables, graphs, percentages, frequencies, mean, medians and standard deviations. After measurement of weight and height, body mass index was calculated automatically. Similarly geriatric depression score was computed using the compute command. The outcome variable malnutrition status was categorized as those with malnutrition, at risk of malnutrition and normal nutritional status based on the overall sum score of each subject. Malnutrition was assessed using the full MNA score (out of 30) and calculated using the compute command in SPSS. Those who scored below 17 (malnourished), 17 to 23.5 (at risk of malnutrition) and otherwise normal [7]. At the same time the GDS was calculated using 15 items yes or no (1- yes for the presence of one of the depression symptoms. A GDS of 10 to 15 were considered as severe while, 5 to 9 as mild depression and no depression otherwise.

Then both bivariate and multivariable ordinal logistic regression were conducted using crude and adjusted odds Ratio at 95\% confidence interval reported. The odds ratio corresponding to each variable were calculated using PLum command and by exporting the result to excel as needed. Those variables with $P$ value less than 0.20 and important predictors in bivariate analysis were taken to multivariable ordinal logistic regression analysis. $\mathrm{P}$ value less than 0.05 at multivariable analysis were declared as statistically significant association.

\section{Variables}

Nutritional status of older adults (ordinal scale) was the dependent variable whereas, demographic variables (age, sex, income, occupation, pension, education, and parental support), smoking, depression, appetite, chronic disease, oral health problems and physical exercise were independent variables.

\section{Ethical considerations}

Ethical clearance was taken from Dire Dawa University Research and Technology Interchange directorate. Then, it was forwarded to Harari health bureau then to respective woredas and Kebles. Verbal informed consent were obtained from the respondents who are able to give consent otherwise it will be taken from caregivers or their parents. The data is used only for this research only and also in the future. Personal identification of clients like name, personal location and others were not be recorded. For those having severe malnutrition, nutritional counseling were done. In addition, counseling in order to have health care service in the nearest health facility were advised in advance for them and caregiver.

\section{Results}

\section{Basic characteristics of participants}

In this particular study, a total of 592 respondents were recorded with overall response rate of $93.4 \%$. Regarding religion, a total of $290(50.3 \%)$ and 244 (42.4\%) were followers of Islam and orthodox Christianity respectively. Almost half, 292 (49.3\%) were married followed by 212 (35.8) of their partner has died. Majority of them, 316 (54\%) were illiterate while, $176(30.1 \%$ attended primary school. Majority of respondents, 508 (85.8\%) and 522 (88.2\%) were from rural area and live with their relatives respectively. With respect to occupation of respondents, $308(52 \%)$ and 209 (35.3\%) reported that they do not have work and involved in private work. A total of 406 $(69.2 \%)$ reported that they did not have any pension fee (Table 1). Regarding perceived health status of older adults, about 37, 47 and $16 \%$ of them perceived as good, average and poor respectively.

Regarding lifestyle characteristics, a total of 210 (35.5\%) had habit of khat chewing. While about 48 (8.1\%) smoke cigarette. In addition, 349 (59\%) and 330 (55.7\%) had at least one chronic illness and insomnia respectively with 196 (33.1\%) had history of hospitalization in the previous year. However, only $135(22.8 \%)$ had habit of physical activity. More than half, 381(644\%) reported to have some sort of dental problem or eating problem (Table 2). 
Table 1 Basic characteristics of elderly peoples in Harari Region, Eastern Ethiopia, 2019

\begin{tabular}{|c|c|c|}
\hline Characteristics & Number & Percent \\
\hline \multicolumn{3}{|l|}{ Sex $(n=592)$} \\
\hline Male & 291 & 49.2 \\
\hline Female & 301 & 50.8 \\
\hline \multicolumn{3}{|l|}{ Religion $(n=576)$} \\
\hline Muslim & 290 & 50.3 \\
\hline Orthodox & 244 & 42.4 \\
\hline Protestant & 40 & 6.9 \\
\hline Catholic & 2 & 0.3 \\
\hline \multicolumn{3}{|l|}{ Marital Status $(n=592)$} \\
\hline Married & 292 & 49.3 \\
\hline Single & 18 & 3.0 \\
\hline Divorced & 70 & 11.8 \\
\hline Widowed & 212 & 35.8 \\
\hline \multicolumn{3}{|c|}{ Educational Status $(n=585)$} \\
\hline Illiterate & 316 & 54.0 \\
\hline Primary School & 176 & 30.1 \\
\hline Grade 8-12 & 66 & 11.3 \\
\hline College And Above & 27 & 4.6 \\
\hline \multicolumn{3}{|l|}{ Residence $(n=592)$} \\
\hline Urban & 84 & 14.2 \\
\hline Rural & 508 & 85.8 \\
\hline \multicolumn{3}{|l|}{ Live With ( $n=592)$} \\
\hline Alone & 70 & 11.8 \\
\hline With Others & 522 & 88.2 \\
\hline \multicolumn{3}{|c|}{ Do You Work At The Moment Pension Fee $(n=587)$} \\
\hline Yes & 271 & 46.2 \\
\hline No & 316 & 53.8 \\
\hline \multicolumn{3}{|c|}{ Who Cover Your Expense $(n=585)$} \\
\hline Yes & 258 & 43.6 \\
\hline No & 327 & 55.2 \\
\hline \multicolumn{3}{|c|}{ Health Insurance $(n=586)$} \\
\hline Yes & 94 & 16 \\
\hline No & 492 & 84 \\
\hline \multicolumn{3}{|l|}{ Occupation $(n=590)$} \\
\hline Farmer & 39 & 6.6 \\
\hline Private & 209 & 35.3 \\
\hline Government & 34 & 5.7 \\
\hline Not Have Work & 308 & 52.0 \\
\hline \multicolumn{3}{|l|}{ Pension Fee $(n=587)$} \\
\hline Yes & 168 & 28.6 \\
\hline No & 406 & 69.2 \\
\hline Not Reached & 13 & 2.2 \\
\hline
\end{tabular}

In general, a total of 187 (31.6\%) of respondents had screening positive for geriatric depression with 131 (22.1\%) and 56 (9.5\%) had moderate (GDS score of 5 to 9) and severe depression (GDS score of 10 to 15) respectively. While, more than half, 405 (68.4\%) were negative (no depression) for Geriatric depression screening tool short version (Table 3).

\section{Nutritional status of older adults people}

In this study, majority 306 (51.7\%) and 193 (32.1\%) were found to be at risk of malnutrition (MNA score from 17 to 24) and not malnourished (MNA score greater than or equals to 24$)$. While, 93 (15.7\%) were malnourished (MNA score below 17) according to full MNA malnutrition screening tool (Fig. 1).

Factors associated with malnutrition among older adults Those respondents on pension, residing rural, with economic shortages, without health insurance, suffering from chronic pain, previous hospitalizations and positive for depression were predictors of malnutrition among older adults. Old ages from rural had higher log odds for being malnourished. Similarly, older age with history of chronic pain $(\mathrm{COR}=170 ; p=0.008)$ and hospitalization $(\mathrm{COR}=3.57 ; p$ value less than 0.0001$)$ had four fold higher odds of being malnourished (Tables 2 and 4).

The outcome variable, malnutrition is ordered in form of normal, at risk of malnutrition and malnourished. The OLS predict the probability of higher odds for malnutrition as compared to normal nutritional status by each predictor variables. The proportional odds assumption is partially full filled and other assumptions of OLS were met. The predicted regression coefficients are interpreted as predicted change in log odds of being malnourished as compared of normal per unit increase in predictor variables controlling for other variables. While, odds ratio is interpreted for categorical predictors.

The full model, including important predictors of malnutrition among Older adults, shows a significant improvement in model fitness under -2 log likelihood for the intercept only and with the full model ( $\mathrm{P}$ less than $0.0001)$. In addition, both the deviance $(p=0.08)$ and pearson chi-square test $(P=0.01)$ were not significant (above 5\%) which showed better fitted OLS.

The predicted log odds of being malnourished (lower MNA score) was higher among those from rural residents $(\beta=0.73(\mathrm{se}=0.21), p=0.005)$. Older adults who are not on work and on pension $(\mathrm{AOR}=1.3195 \% \mathrm{CI}$ : $0.87-1.95)$ and did not have health insurance (AOR = 1.58 ; $95 \%$ CI; $0.97-2.58)$ had 31 and 58\% higher predicted odds of being malnourished than those who are on work respectively. In addition, those who have chronic pain history (AOR $=1.70 ; 95 \%$ CI: $1.15-2.51$ ), 
Table 2 Factors associated with Malnutrition among elderly people in Harari region, Eastern Ethiopia

\begin{tabular}{|c|c|c|c|c|c|c|c|}
\hline \multirow[t]{2}{*}{ Factors } & \multicolumn{6}{|c|}{ Nutritional status } & \multirow[t]{2}{*}{$X^{2}$ ( $p$ value) } \\
\hline & \multicolumn{2}{|c|}{$\begin{array}{l}\text { Malnourished } \\
\text { No (freq.) }\end{array}$} & \multicolumn{2}{|c|}{ At risk of malnutrition No (freq.) } & \multicolumn{2}{|c|}{$\begin{array}{l}\text { Normal } \\
\text { No (freq.) }\end{array}$} & \\
\hline Male & 43 & $15 \%$ & 147 & $51 \%$ & 101 & $35 \%$ & $1.16(0.281)$ \\
\hline Female & 50 & $17 \%$ & 159 & $53 \%$ & 92 & $31 \%$ & \\
\hline \multicolumn{8}{|l|}{ Live with whom } \\
\hline Alone & 8 & $11 \%$ & 37 & $53 \%$ & 25 & $36 \%$ & $0.95(0.329)$ \\
\hline With others & 85 & $16 \%$ & 269 & $52 \%$ & 168 & $32 \%$ & \\
\hline \multicolumn{8}{|l|}{ Religion } \\
\hline Muslim & 69 & $24 \%$ & 151 & $52 \%$ & 70 & $24 \%$ & $34.2(0.000)$ \\
\hline Christian & 24 & $8 \%$ & 155 & $51 \%$ & 123 & $41 \%$ & \\
\hline \multicolumn{8}{|l|}{ Marital status } \\
\hline Married & 24 & $8 \%$ & 157 & $54 \%$ & 111 & $38 \%$ & $42.3(0.000)$ \\
\hline Divorced & 13 & $15 \%$ & 55 & $63 \%$ & 20 & $23 \%$ & \\
\hline Widowed & 56 & $26 \%$ & 94 & $44 \%$ & 62 & $29 \%$ & \\
\hline \multicolumn{8}{|l|}{ Educational status } \\
\hline Illiterate & 76 & $24 \%$ & 153 & $48 \%$ & 87 & $28 \%$ & $32.16(0.000)$ \\
\hline Primary school & 13 & $7 \%$ & 104 & $59 \%$ & 59 & $34 \%$ & \\
\hline Grade8 \& above & 4 & $4 \%$ & 49 & $49 \%$ & 47 & $47 \%$ & \\
\hline \multicolumn{8}{|l|}{ Work at the moment } \\
\hline Yes & 11 & $4 \%$ & 144 & $53 \%$ & 116 & $43 \%$ & $53.4(0.000)$ \\
\hline No & 80 & $25 \%$ & 162 & $51 \%$ & 74 & $23 \%$ & \\
\hline \multicolumn{8}{|l|}{ Occupation } \\
\hline Farmer & 1 & $3 \%$ & 19 & $49 \%$ & 19 & $49 \%$ & $47.60(0.000)^{*}$ \\
\hline Private & 11 & $5 \%$ & 111 & $53 \%$ & 87 & $42 \%$ & \\
\hline Government & 1 & $3 \%$ & 20 & $59 \%$ & 13 & $38 \%$ & \\
\hline Not have work & 79 & $26 \%$ & 155 & $50 \%$ & 74 & $24 \%$ & \\
\hline \multicolumn{8}{|l|}{ Residence } \\
\hline Urban & 4 & $5 \%$ & 35 & $43 \%$ & 42 & $52 \%$ & $18.41(0.000)$ \\
\hline Rural & 87 & $17 \%$ & 271 & $53 \%$ & 150 & $30 \%$ & \\
\hline \multicolumn{8}{|c|}{ Who covers your expense? } \\
\hline Yes & 13 & $5 \%$ & 140 & $54 \%$ & 105 & $41 \%$ & $6.16(0.013)^{*}$ \\
\hline No & 77 & $24 \%$ & 164 & $50 \%$ & 86 & $26 \%$ & \\
\hline \multicolumn{8}{|l|}{ Health insurance } \\
\hline Yes & 5 & $5 \%$ & 53 & $56 \%$ & 36 & $38 \%$ & $34.6(0.000)$ \\
\hline No & 85 & $17 \%$ & 252 & $51 \%$ & 155 & $32 \%$ & \\
\hline \multicolumn{8}{|l|}{ Pension fee } \\
\hline Yes & 34 & $20 \%$ & 85 & $51 \%$ & 49 & $29 \%$ & $3.3(0.071)^{*}$ \\
\hline No & 59 & $14 \%$ & 221 & $52 \%$ & 144 & $34 \%$ & \\
\hline \multicolumn{8}{|l|}{ Chronic pain } \\
\hline Yes & 89 & $26 \%$ & 179 & $51 \%$ & 81 & $23 \%$ & $67.1(0.0001)$ \\
\hline No & 4 & $2 \%$ & 127 & $52 \%$ & 112 & $46 \%$ & \\
\hline \multicolumn{8}{|l|}{ Insomnia } \\
\hline Yes & 71 & $22 \%$ & 169 & $51 \%$ & 90 & $27 \%$ & $20.3(0.0001)$ \\
\hline
\end{tabular}


Table 2 Factors associated with Malnutrition among elderly people in Harari region, Eastern Ethiopia (Continued)

\begin{tabular}{|c|c|c|c|c|c|c|c|}
\hline \multirow{3}{*}{$\begin{array}{l}\text { Factors } \\
\text { No }\end{array}$} & \multicolumn{6}{|c|}{ Nutritional status } & \multirow[t]{3}{*}{$x^{2}$ ( $p$ value) } \\
\hline & \multicolumn{2}{|c|}{$\begin{array}{l}\text { Malnourished } \\
\text { No (freq.) }\end{array}$} & \multicolumn{2}{|c|}{ At risk of malnutrition No (freq.) } & \multicolumn{2}{|c|}{$\begin{array}{l}\text { Normal } \\
\text { No (freq.) }\end{array}$} & \\
\hline & 22 & $8 \%$ & 137 & $52 \%$ & 103 & $39 \%$ & \\
\hline \multicolumn{8}{|l|}{ Khat chewing } \\
\hline Yes & 20 & $10 \%$ & 114 & $54 \%$ & 76 & $36 \%$ & $6.58(0.01)$ \\
\hline No & 72 & $19 \%$ & 192 & $50 \%$ & 117 & $31 \%$ & \\
\hline \multicolumn{8}{|l|}{ Smoking } \\
\hline Yes & 71 & $22 \%$ & 169 & $51 \%$ & 90 & $27 \%$ & $4.26(0.039)$ \\
\hline No & 22 & $8 \%$ & 137 & $52 \%$ & 103 & $39 \%$ & \\
\hline \multicolumn{8}{|c|}{ Hospitalization in previous year } \\
\hline Yes & 60 & $31 \%$ & 99 & $51 \%$ & 37 & $19 \%$ & $57.3(0.0001)$ \\
\hline No & 33 & $8 \%$ & 207 & $52 \%$ & 156 & $39 \%$ & \\
\hline \multicolumn{8}{|l|}{ Chewing problem } \\
\hline Yes & 70 & $18 \%$ & 197 & $52 \%$ & 114 & $30 \%$ & $6.7(0.01)$ \\
\hline No & 23 & $11 \%$ & 109 & $52 \%$ & 79 & $37 \%$ & \\
\hline \multicolumn{8}{|l|}{ Physical exercise } \\
\hline Yes & 15 & $11 \%$ & 75 & $56 \%$ & 45 & $33 \%$ & $1.2(0.296)$ \\
\hline No & 78 & $17 \%$ & 231 & $51 \%$ & 148 & $32 \%$ & \\
\hline \multicolumn{8}{|l|}{ Depression } \\
\hline Depression & 75 & $40 \%$ & 84 & $45 \%$ & 28 & $15 \%$ & $106.02(0.0001)$ \\
\hline No depression & 18 & $4 \%$ & 222 & $55 \%$ & 165 & $41 \%$ & \\
\hline
\end{tabular}

previous hospitalization $(\mathrm{AOR}=1.59: 95 \% \mathrm{CI}: 1.27-2.38)$ and not able to cover their personal expense $(\mathrm{AOR}=$ 1.61: $95 \%$ CI: $1.12-2.30$ ) were 70,60 and $61 \%$ significantly higher $\log$ odds of being malnourished (lower MNA score than higher) respectively. The relationship between previous hospitalizations with malnutrition among Older adults is moderated significantly by the presence of chronic pain $(\beta=0.113, p=0.015)$ (Table 5).

\section{Discussion}

This study was aimed to assess the magnitude of malnutrition risk and its predictors among the older adults in the eastern part of Ethiopia. The finding revealed that, $32.1 \%(28.2-35.8 \%)$ and $15.7 \%(12.8-18.6 \%)$ were at risk of malnutrition and malnourished based on validated MNA screening tool respectively. This is indicative of high risks of malnutrition and all its bad consequences in the overall health of individuals (12). Similarly, evidences from other regions of Ethiopia showed that, $28.3 \%$ [17], 22\% [18], 21.9\% [14], $17.6 \%$ (95\% CI: $15.0-$ 20.2) [19], $17.1 \%$ [20], $12.5 \%$ in Sirilanka [21] and $24.8 \%$ in Nepal [22] were malnourished.

This burden of malnutrition can still be above this, due to potentially higher incidence of risk factors for malnutrition. It might be expected that the burden will be higher among institutionalized elder people frailty in institutionalized persons $(\beta: 0.22 ; P=0.036)$ [23]. However, the current study incorporates both urban $(4.9 \%)$ and rural area (17.1\%) which makes representative. In addition, the use of BMI as tool to screen for malnutrition instead of MNA tool, may make a difference even if, it has high predictive power for malnutrition [17].

Rural residents were found to be at increased risk of being malnourished as compared to urban residents $(\mathrm{AOR}=2.08 ; 95 \% \mathrm{CI}: 1.25-3.45)$. This is attributed to differences in socioeconomic status, dietary habit and other confounding factors make the rural area at risk of malnutrition. It may also be related to lower access to health care, sanitation facility and educational status which makes disease, and food intake shortage a major problem [24, 25].

Economic dependences characterized by being pension user, not able to cover personal expenses and those without any health insurance were vulnerable to a higher probability of being malnourished. These economic instabilities decrease food access and dietary diversity ultimately resulting in malnutrition among the older adults. One study showed that less diversified diet intake increases risk of malnutrition among the older population [19]. This indicates, the need for strategies and interventions targeting the basic and underlying contextspecific causes of malnutrition in addition to addressing 
Table 3 Detail report on the outcomes of GDS short form screening for elderly people in Harari Region, Eastern Ethiopia

\begin{tabular}{|c|c|c|c|}
\hline \multicolumn{2}{|l|}{ GDS dimensions } & \multirow{2}{*}{$\begin{array}{l}\text { Frequency } \\
526\end{array}$} & \multirow{2}{*}{$\begin{array}{l}\text { Percentage } \\
88.9\end{array}$} \\
\hline Are You basically Satisfied with your life? & Yes & & \\
\hline & No & 66 & 11.1 \\
\hline \multirow[t]{2}{*}{ Have you dropped many of your activities and interests? } & Yes & 197 & 33.3 \\
\hline & No & 395 & 66.7 \\
\hline \multirow[t]{2}{*}{ Do you feel that your life is empty? } & Yes & 74 & 12.5 \\
\hline & No & 518 & 87.5 \\
\hline \multirow[t]{2}{*}{ Do you often got bored? } & Yes & 118 & 19.9 \\
\hline & No & 474 & 80.1 \\
\hline \multirow[t]{2}{*}{ Are you in a good sprit most of time? } & Yes & 421 & 71.1 \\
\hline & No & 171 & 28.9 \\
\hline \multirow[t]{2}{*}{ Are you afraid that something bad is going to happen to you? } & Yes & 112 & 18.9 \\
\hline & No & 480 & 81.1 \\
\hline \multirow[t]{2}{*}{ Do you feel happy most of the time? } & Yes & 444 & 75.0 \\
\hline & No & 148 & 25.0 \\
\hline \multirow[t]{2}{*}{ Do you often feel hopeless? } & Yes & 100 & 16.9 \\
\hline & No & 492 & 83.1 \\
\hline \multirow[t]{2}{*}{ Do you prefer to stay at home rather than going out? } & Yes & 227 & 38.3 \\
\hline & No & 365 & 61.7 \\
\hline \multirow[t]{2}{*}{ Do you feel that you have more problem with memorythan most? } & Yes & 140 & 23.6 \\
\hline & No & 452 & 76.4 \\
\hline \multirow[t]{2}{*}{ Do you think it is wonderful to be alive now? } & Yes & 444 & 75.0 \\
\hline & No & 148 & 25.0 \\
\hline \multirow[t]{2}{*}{ Do you feel worthless the way you are now? } & Yes & 87 & 14.7 \\
\hline & No & 505 & 85.3 \\
\hline \multirow[t]{2}{*}{ Do you feel full of energy? } & Yes & 298 & 50.3 \\
\hline & No & 294 & 49.7 \\
\hline \multirow[t]{2}{*}{ Do you feel that your situation is hopeless? } & Yes & 81 & 13.7 \\
\hline & No & 511 & 86.3 \\
\hline \multirow[t]{2}{*}{ Do you think that most people are better off than you are? } & Yes & 173 & 29.2 \\
\hline & No & 419 & 70.8 \\
\hline
\end{tabular}

immediate causes [26]. Other study, also showed that economic inaccessibility were an important risk factors for malnutrition burden [27]. Furthermore, evidence showed that presence of sustainable income is positively related to self-rated health status among old age $(\mathrm{OR}=1.8)$ [28].

Depression is found to increase the nutritional risk among elders (AOR $=1.26$ : 95\% CI: $1.20-1.34$ ). One study indicated that, depression symptom significantly increase nutritional risk ((MNA score 22.86 vs. $24.96, p<0.001$ ) [29]. As depression is not a normal part of aging, rather common mood disorder that significantly affect the dietary intake and physiology which potentially affects the nutritional status. These may be related to increased nutrition risk due to hospitalization ( $p$-value less than 0.0001 ) and not involved actively in work ( $\mathrm{p}$-value less than 0.0001) which makes them less active and at risk for depressive disorder. There should be screening and care for depression among older adults in health facilities. In addition, promoting active living style and reducing sedentary lifestyle could play an important role in reducing malnutrition and its adverse consequences [30-32].

Furthermore, the presence of chronic illness and hospitalization with multiple drug use are important predictors of malnutrition. A review of evidence showed that multiple drug intake negatively affects the nutritional status of the older adults $(\beta$ : $-0.62 ; P=0.001)$. Also, those elders in institutions other than home setting have increased risk of being malnourished [23, 31]. Thus, interventions developing positive lifestyles like physical activity and good dietary habit for reduced chronic diseases risk should get due attention. The inclusion older adults as target for nutrition and health interventions for better health status should be one target. 


\section{Level of malntrition among elderly in Percentage}

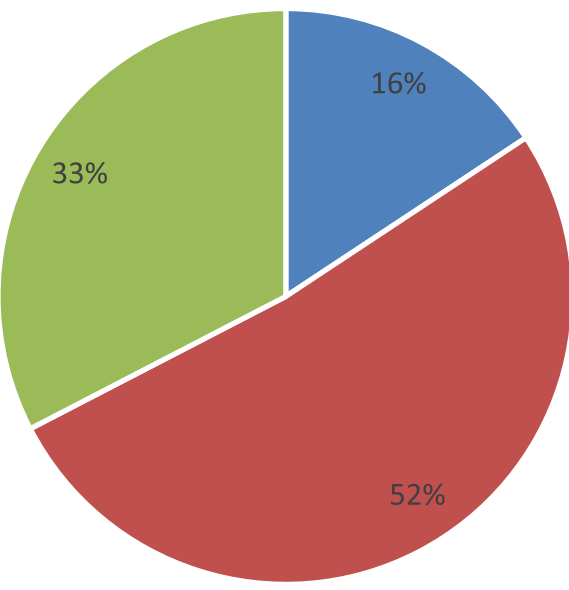

- Malnourished $\quad$ At risk of malnutrition $\quad$ Normal Ntritional status

Fig. 1 Nutritional status of elderly people in Harari Region, Eastern Ethiopia $(n=592)$

However, other confounding situations and variables may interact together to the deterioration of their nutritional status among institutionalized elders [23]. More specifically, the presence of chronic illness, poor caring practice and psychological status may affect food intake and nutritional status. In addition, polypharmacy may have the potential to decrease food intake and other side effects which might increases malnutrition risk [33].

The findings of this study employed validated tool with an overall accuracy of 91\% (sensitivity and specificity of 87.9 and $89.6 \%$ for the established cutoff points) [34]. It also employed valid and reliable anthropometric measurements for better outputs. However, the cross-sectional nature of the study, some slight age-related disorders (curvatures) and measurement may create some errors. The result should be viewed in the light of the above strength and weakness of the study. But, the study pinpoints an important health problem of the neglected society in Ethiopia for programs to design and implement effective interventions addressing the older adults.

Table 4 Bivariate ordinal logistic regression output for prediction of malnutrition among elderly

\begin{tabular}{|c|c|c|c|c|c|}
\hline Variables & $\beta$ & Se $f \beta$ & $\operatorname{Exp}(\beta) O R$ & $P$-value & $95 \% \mathrm{Cl}(\beta)$ \\
\hline Sex (female) & .172 & .157 & 1.19 & 0.272 & $-0.14-0.48$ \\
\hline Residence (Rural) & .997 & .235 & 2.71 & 0.000 & $0.54-1.46$ \\
\hline Education (higher) & -.565 & .107 & 0.57 & 0.000 & $-0.78--0.36$ \\
\hline Living (with others) & .224 & .243 & 1.25 & 0.357 & $-0.253-0.70$ \\
\hline Marital status (separate) & .380 & .088 & 1.46 & 0.000 & $0.21-0.55$ \\
\hline Pension (yes) & .298 & .176 & 1.35 & 0.091 & $-0.05-0.64$ \\
\hline Work at the moment (No) & 1.173 & .168 & 3.23 & 0.000 & $0.85-1.50$ \\
\hline Support (yes) & -.919 & .165 & 0.40 & 0.000 & $-1.24-0.60$ \\
\hline Health insurance (yes) & -.484 & .216 & 0.62 & 0.025 & $-0.91-0.06$ \\
\hline Chronic pain (Yes) & 1.346 & .171 & 3.84 & 0.000 & $1.01-1.68$ \\
\hline Hospitalization (Yes) & 1.272 & .179 & 3.57 & 0.000 & $0.92-1.62$ \\
\hline Insomnia (yes) & .700 & .161 & 2.01 & 0.000 & $0.38-1.02$ \\
\hline Physical activity (No) & .171 & .187 & 1.19 & 0.359 & $-0.20-0.54$ \\
\hline Depression (yes) & 1.986 & .200 & 7.29 & 0.000 & $1.59-2.38$ \\
\hline
\end{tabular}


Table 5 Parameters for predictors of malnutrition level as compared to normal and at risk of malnutrition (multivariable OLS model with stepwise backward regression method)

\begin{tabular}{llllll}
\hline Predictors & $\boldsymbol{\beta}$ & Se $\boldsymbol{f} \boldsymbol{\beta}$ & $\boldsymbol{E x p}(\boldsymbol{\beta})$ OR & $\boldsymbol{P}$ value & $\mathbf{9 5 \%}$ Cl of Exp ( $\boldsymbol{\beta})$ \\
\hline Pension fee user (yes) & 0.268 & 0.205 & 1.31 & 0.192 & $0.87-1.95$ \\
Residence (rural) & 0.731 & 0.259 & 2.08 & 0.005 & $1.25-3.45$ \\
Cover personal expense (no) & 0.474 & 0.185 & 1.61 & 0.010 & $1.12-2.30$ \\
Have health Insurance (no) & 0.458 & 0.250 & 1.58 & 0.067 & $0.97-2.58$ \\
Chronic pain (yes) & 0.532 & 0.199 & 1.70 & 0.008 & $1.15-2.51$ \\
Hospitalization in the last year (yes) & 0.464 & 0.205 & 1.59 & 0.023 & $1.27-2.38$ \\
Depression (yes) & 0.233 & 0.028 & 1.26 & 0.001 & $1.20-1.34$ \\
\hline
\end{tabular}

\section{Conclusions}

Malnutrition among old age is a public health concern that needs attention. Economic vulnerability, residence, depression, presence of chronic disease, and hospitalization were important risk factors for malnutrition among old age. The health system needs to give attention to geriatric health and implement screening, health education, and follow-up of older adults' nutritional status.

\section{Supplementary Information}

The online version contains supplementary material available at https://doi. org/10.1186/s12877-020-01911-2

\section{Additional file 1.}

\section{Abbreviations}

Cl: Confidence Interval; EMR: Electronic Medical record; OLR: Ordinal Logistic Regression; OR: Odds Ratio

\section{Acknowledgements}

We thank heath offices, Dire Dawa University, data collectors, and supervisors for their valuable contribution for accomplishment of this study.

\section{Authors' contributions}

AA participated in from initial inception, proposal writing, preparing data collection tool, pretesting, data collection, data analysis, result write up, preparation of manuscript to submission. IY and AK participated in inception, preparing data collection tool, pretesting, data collection, and review the final submission. All authors have read and approved the final manuscript.

\section{Funding}

We thank Dire Dawa University for providing financial and administrative support grant for our research. The content is solely the responsibility of the authors and does not represent the official views of the university. The University had no role in the design and conduct of the study; collection, management, analysis, and interpretation of the data; preparation, review, or approval of the manuscript; and decision to submit the manuscript for publication.

\section{Availability of data and materials}

All data generated or analyzed during this study are included in this published article.

\section{Ethics approval and consent to participate}

This research was reviewed and ethically approved by independent Research ethical review committee named Dire Dawa University ethical review committee (Reference number; not applicable). Then a verbal informed consent considering their free will to participate in the study, confidentiality of their information and each participant was obtained. Since the data do notinvolve biological sample, verbal informed consent was approved and obtained from the ethical review committee. All possible ethical cares were respected throughout the conduct of research project.

\section{Consent for publication}

Not applicable.

\section{Competing interests}

Authors declare that they have no competing interest.

\section{Author details}

'Department of Public Health, Dire Dawa University, Dire Dawa, Ethiopia.

${ }^{2}$ School of Medicine, Dire Dawa University, Dire Dawa, Ethiopia.

Received: 29 July 2020 Accepted: 17 November 2020

Published online: 23 November 2020

\section{References}

1. Wan He DG, Kowal P. In: U.S. Census Bureau, et al., editors. An Aging World: 2015: International Population Reports; 2016.

2. United Nation Economic Commission for Africa (UNECA). The Demographic Profiles of African Countries, United Nation Economic Commission for Africa 2016: Addis Ababa, Ethiopia: p. 10-20.

3. Charles T, Assefa H, Tesfayi G, Hassan A. In: Food and Nutrition Security, editor. Population Dynamics, Food/Nutrition Security and Health in Ethiopia: Delicate Balance of Vulnerability \& Resilience. Addis Ababa: IUSSP Marrakech; 2009. p. 1-4.

4. WHO, Global health and Aging, D.o.H.a.H. Services, Editor 2016, National Institute on Aging/Health, USA: USA.

5. Tewodros HZ. Life after Life: An Assessment of Elderly Institutional Care in Addis Ababa City (in Particular Reference to Mekedonia Home for the Elderly and Mentally Disabled). Global J Human Soc Health. 2017;17(2):1-5.

6. RibeiRo R, RoSa M, Bozzetti M, Ribeiro RS, Rosa MI, Bozzetti MC. Malnutrition and associated variables in an elderly population of Criciúma, SC. Rev Assoc Med Bras (1992). 2011;57(1):56-61.

7. Nestle Nutrition Institute. A guide to completing the Mini Nutritional Assessment - Short Form (MNA ${ }^{\oplus}$-SF): Nestle Nutrition Institute; Rue d'Entredeux-Villes 10, 1814 La Tour-de-Peilz, Switzerland; 2006.

8. Leslie W, Hankey C. Aging, nutritional status and health. Healthcare. 2015;3: 648-58.

9. Help Age International. Vulnerability of Older People in Ethiopia: The Case of Oromia, Amhara and SNNP Regional States. Addis Ababa: Help Age International in Ethiopia; 2013.

10. Pearce, S. Nutrition and Malnutrition in the Elderly. 2014 [cited December 7, 2018; Available from: http://www.uth.tmc.edu/hgec/GemsAndPearls/ healthPromotions_Nutrition.html.

11. Cawood A, Elia M, Stratton R. Systematic review and meta-analysis of the effects of high protein oral nutritional supplements. Ageing Res Rev. 2012 11:278-96.

12. Söderström L. Nutritional status among older people Risk factors and consequences of malnutrition, in Department of Public Health and Caring Sciences, Clinical Nutrition and Metabolism. Västerås: Uppsala University; 2013 
13. van Bokhorst-de van der Schueren MA, Lonterman-Monasch S, de Vries OJ, Danner SA, Kramer MH, et al. Prevalence and determinants for malnutrition in geriatric outpatients. Clin Nutr. 2013;32(6):1007-11.

14. Tessfamichael D, Gete AA, Wassie MM. High prevalence of Undernutrition among elderly people in Northwest Ethiopia: a cross sectional study. J Nutr Health Food Sci. 2014;2(4):1-5.

15. Mundi, I. Ethiopian Demographic profile 2017. Https://www.indexmundi. com/ethiopia/demographics_profile.html. World Countries fact book 2017 [cited 2018 Dec 29].

16. De-Luis DA, Mongil RL, Sagrado MG, Trigo JAL, Mora PF, et al. Evaluation of the mini-nutritional assessment short-form (MNA-SF): among institutionalized older patients in Spain. Nutr Hosp. 2011;26(6):1350-4.

17. Hailemariam $\mathrm{H}$, Singh $\mathrm{P}$, Fekadu T. Evaluation of mini nutrition assessment (MNA) tool among community dwelling elderly in urban community of Hawassa city, Southern Ethiopia. BMC Nutrition. 2016;2(1):11.

18. Adhana Z, Tessema G, Getie G. Prevalence of Undernutrition and associated factors among people of old age in Debre Mrkos town, north West Ethiopia. J Aging Res Clin Practice. 2019;8:20-6.

19. Legesse M, Abebe Z, Woldie H. Chronic energy deficiency and associated factors among older population in Ethiopia: a community based study. PLoS One. 2019;14(4):e0214861.

20. Kidest W, Asseffa NA, Gemebo TD, Astawesegn FH. Predictors of undernutrition among the elderly in Sodo zuriya district Wolaita zone, Ethiopia. BMC Nutr. 2019;5(1):50.

21. Damayanthi HDWT, Moy FM, Abdullah KL, Dharmaratne SD. Prevalence of malnutrition and associated factors among community-dwelling older persons in Sri Lanka: a cross-sectional study. BMC Geriatr. 2018;18(1):199.

22. Tamang MK, Yadav UN, Hosseinzadeh H, Kafle B, Paudel G, et al. Nutritional assessment and factors associated with malnutrition among the elderly population of Nepal: a cross-sectional study. BMC Res Notes. 2019;12(1):246.

23. Fávaro-Moreira NC, Krausch-Hofmann S, Matthys C, Vereecken C, Vanhauwaert $E$, et al. Risk factors for malnutrition in older adults: a systematic review of the literature based on longitudinal data. Adv Nutr. 2016;7(3):507-22.

24. Visvanathan R, Newbury J, Chapman I. Malnutrition in older people screening and management strategies. J Aust Fam Physician. 2004;33(10):799-806.

25. Kristi J, Carla M, Barry P. Underweight, Undernutrition, and the aging. Today's Res Aging. 2007:8:1-5.

26. Timpini A, Facchi E, Cossi S, Ghisla MK, Romanelli G, et al. Self-reported socio-economic status, social, physical and leisure activities and risk for malnutrition in late life: a cross-sectional population-based study. J Nutr Health Aging. 2011;15(3):233-8.

27. Donini LM, Scardella P, Piombo L, Neri B, Asprino R, et al. Malnutrition in elderly: social and economic determinants. J Nutr Health Aging. 2013;17(1):9-15.

28. Woo J, Yu R, Cheung K, Lai ETC. How Much Money Is Enough? Poverty and Health in Older People. J Nutr Health Aging. 2020:1-7.

29. German L, Feldblum I, Bilenko N, Castel H, Harman-Boehm I, et al. Depressive symptoms and risk for malnutrition among hospitalized elderly people. J Nutr Health Aging. 2008;12(5):313.

30. Masanovic B, Popovic S, Bjelica D, Zoric G. The effects of physical activity on depressive symptoms among elderly people: a systematic review, In World Congress of Performance Analysis of Sport XIIAt. Opatija;World Congress: 2018.

31. O'Keeffe M, Kelly M, O'Herlihy E, O'Toole PW, Kearney PM, et al. Potentially modifiable determinants of malnutrition in older adults: a systematic review. Clin Nutr. 2019;38(6):2477-98.

32. Jung SE, Bishop AJ, Kim M, Hermann J, Kim G, et al. Nutritional status of rural older adults is linked to physical and emotional health. J Acad Nutr Diet. 2017;117(6):851-8.

33. Jyrkkä J, Enlund H, Lavikainen P, Sulkava R, Hartikainen S. Association of polypharmacy with nutritional status, functional ability and cognitive capacity over a three-year period in an elderly population. Pharmacoepidemiol Drug Saf. 2011;20:514-22.

34. Woldekidan MA, Haile D, Shikur B, Gebreyesus SH. Validity of Mini Nutritional Assessment tool among an elderly population in Yeka sub-city, Addis Ababa, Ethiopia. South African J Clin Nutr. 2020:33: 1-7.

\section{Publisher's Note}

Springer Nature remains neutral with regard to jurisdictional claims in published maps and institutional affiliations.

\section{Ready to submit your research? Choose BMC and benefit from:}

- fast, convenient online submission

- thorough peer review by experienced researchers in your field

- rapid publication on acceptance

- support for research data, including large and complex data types

- gold Open Access which fosters wider collaboration and increased citations

- maximum visibility for your research: over $100 \mathrm{M}$ website views per year

At $\mathrm{BMC}$, research is always in progress.

Learn more biomedcentral.com/submissions 